\title{
INATIVAÇÃO POR OXIDAÇÃO FOTOCATALÍTICA DE Escherichia coli E Pseudomonas sp.
}

\section{Angela Cristina de Souza Cordeiro*}

Departamento de Saneamento e Saúde Ambiental, Escola Nacional de Saúde Pública Sérgio Arouca, Fundação Oswaldo Cruz, Rua Leopoldo Bulhões, 1480, 21041-210 Rio de Janeiro - RJ

\section{Selma Gomes Ferreira Leite}

Departamento de Engenharia Bioquímica, Escola de Química, Universidade Federal do Rio de Janeiro, Cidade Universitária, Ilha do Fundão, 21949-900 Rio de Janeiro - RJ

Márcia Dezotti

COPPE, Universidade Federal do Rio de Janeiro, Cidade Universitária, Ilha do Fundão, 21945-970 Rio de Janeiro - RJ

Recebido em 5/5/03; aceito em 29/3/04; publicado na web em 19/7/04

\begin{abstract}
INACTIVATION OF Escherichia coli AND Pseudomonas sp. BY PHOTOCATALYTIC OXIDATION. This study presents the bactericidal activity of titanium dioxide photocatalysis, using as model Escherichia coli and Pseudomonas sp. cells. It was observed that the process efficiency is related to initial cell concentration, light intensity, UV irradiation exposure time, $\mathrm{TiO}_{2}$ concentration increase. The ultimate removal efficiency was above $99.9 \%$.
\end{abstract}

Keywords: photocatalysis; titanium dioxide; bactericidal activity.

\section{INTRODUÇÃO}

Muitos segmentos da sociedade estão preocupados com as questões ambientais e vêm, cada vez mais freqüentemente, divulgando suas insatisfações com os acidentes ambientais, como os descartes tóxicos, lençóis freáticos contaminados, poluição do ar, disposição de contaminantes no solo, descartes de efluentes em rios e mares, entre outros. Assim, as exigências em relação às leis ambientais em todo o mundo vêm se tornando cada vez mais exigentes, principalmente devido ao aumento da conscientização em relação à saúde pública e aos riscos ecológicos associados à poluição ambiental. Os tratamentos primários e secundários de águas residuárias industriais e urbanas não eliminam completamente os riscos infecciosos e tóxicos já que, após estes tratamentos, substâncias tóxicas e recalcitrantes de difícil degradação e microrganismos patogênicos ainda estão presentes nos efluentes tratados ${ }^{1}$. Por este motivo, nas últimas décadas, várias pesquisas vêm sendo desenvolvidas, visando o aprimoramento e desenvolvimento de tecnologias eficazes para o tratamento de resíduos e redução de poluentes, tendo sempre como base o requisito custo-benefício.

Os Processos Oxidativos Avançados (POA) são tecnologias alternativas que, embora façam uso de diferentes sistemas de reação, envolvem a geração de radicais hidroxila $\left({ }^{\circ} \mathrm{OH}\right)$ altamente oxidantes. Devido à alta reatividade, esses radicais podem reagir com uma grande variedade de compostos orgânicos. O interesse pelos POA tem crescido enormemente, por serem consideradas tecnologias limpas, podendo, em muitas situações, atingir a completa mineralização dos poluentes ${ }^{2}$. Por outro lado, a decomposição parcial de contaminantes orgânicos não biodegradáveis, tais como aromáticos halogenados, gera intermediários biodegradáveis ${ }^{3}$. Assim, a combinação de um POA seguido de um processo biológico parece, do ponto de vista econômico, bastante promissor.

Entre os POA, a fotocatálise heterogênea tem se mostrado uma tecnologia promissora na oxidação/degradação de contaminantes orgânicos, visando o controle ambiental. Muitos catalisadores têm sido

*e-mail: scangela@ensp.fiocruz.br testados, sendo que o dióxido de titânio $\left(\mathrm{TiO}_{2}\right)$, na forma cristalina anatase, parece ter as características mais importantes, como alta estabilidade, bom desempenho e baixo custo ${ }^{2}$. O processo envolve a geração de pares elétron-lacuna $\left(\mathrm{e}^{-} / \mathrm{h}^{+}\right)$, quando um óxido de metal semicondutor é ativado por radiação ultravioleta, com energia maior ou igual à do seu "bandgap". Essas espécies podem se recombinar ou migrar para a superfície do catalisador, reagindo com espécies adsorvidas. O considerável poder redutor dos elétrons fotogerados permite a redução de alguns metais e do oxigênio dissolvido, formando o íon radical superóxido $\left(\mathrm{O}_{2}^{-}\right)$. $\mathrm{O}$ oxigênio apresenta uma importante função como seqüestrador de elétrons, impedindo a recombinação do par $\mathrm{e}^{-} / \mathrm{h}^{+}$, que é apontada como o principal fator limitante para o rendimento do processo ${ }^{4,5}$. Os buracos fotogerados, poderosos agentes oxidantes, são capazes de gerar radicais hidroxila $\left({ }^{\circ} \mathrm{OH}\right)$, oxidando moléculas de água $\left(\mathrm{ou}^{-} \mathrm{OH}\right)$ previamente adsorvidos na superfície do semicondutor. Embora seja considerado o passo primário no mecanismo oxidativo, o ataque do radical ${ }^{\circ} \mathrm{OH}$ sobre $\mathrm{o}$ substrato, mecanismos de oxidação direta via lacunas fotogeradas e via espécies reativas de oxigênio são também possíveis, embora com menor freqüência ${ }^{5}$. Muitas pesquisas têm sido desenvolvidas em vários países, visando maior adequação e otimização do processo fotocatalítico para sua utilização, tanto no âmbito industrial como na saúde pública. Além de promover a total mineralização de uma grande variedade de contaminantes orgânicos, as fotoxidações com $\mathrm{TiO}_{2}$ são promissoras para a eliminação de microrganismos em muitas aplicações, como materiais autolimpantes e auto-esterilizantes. No Japão, uma das aplicações mais importantes da tecnologia fotocatalítica é o uso de azulejos de cerâmica auto-esterilizantes para hospitais, particularmente em salas cirúrgicas. Ao contrário dos bactericidas comuns, os azulejos revestidos com $\mathrm{TiO}_{2}$ são continuamente ativos, enquanto houver iluminação ${ }^{6}$.

Visando a implementação de sistemas fotocatalíticos contínuos em grande escala, diversos estudos sobre a inativação de microrganismos, envolvendo bactérias, protozoários, vírus e fungos, vêm sendo realizados tanto na água como no ar, objetivando a desinfecção de efluentes, de águas para abastecimento e de ambientes interiores sujeitos a contaminação ${ }^{7-11}$. 
Neste estudo foram utilizadas culturas de dois gêneros bacterianos. As bactérias Escherichia coli, por serem de fácil cultivo em laboratório e relativamente conhecidas sob o ponto de vista genético, além de serem empregadas como indicador de contaminação fecal, pois têm seu habitat exclusivo no trato intestinal. Sua presença na água indica a possibilidade de também estarem presentes microrganismos entéricos/ patogênicos, ressaltando que alguns sorotipos de E. coli são responsáveis por gastroenterites, sendo a diarréia o principal sintoma. As espécies da bactéria Pseudomonas estão amplamente distribuídas no solo e na água. Embora normalmente não sejam patogênicas, algumas espécies podem causar infecções graves no homem ${ }^{12}$.

Este trabalho teve como objetivo avaliar o desempenho da fotocatálise empregando $\mathrm{TiO}_{2} / \mathrm{UV}$, na descontaminação de águas contendo Escherichia coli e Pseudomonas sp como bactérias-modelo. Partindo-se de diferentes concentrações bacterianas, submetidas à variação do teor do catalisador $\mathrm{TiO}_{2}$, em diferentes intensidades luminosas e tempos de exposição à irradiação UV, a avaliação foi feita baseada na percentagem de sobrevivência destas espécies, antes e após o tratamento.

\section{PARTE EXPERIMENTAL}

\section{Organismos e condições de crescimento}

Os microrganismos-modelo utilizados para o estudo de desinfecção fotocatalítica foram Escherichia coli e Pseudomonas sp., obtidos de um sistema ambiental poluído. Os organismos foram cultivados em meio de gelose simples e incubados a $35-37{ }^{\circ} \mathrm{C}$ por $24-48 \mathrm{~h}$. Após o crescimento, as culturas foram estocadas a $5{ }^{\circ} \mathrm{C}^{13}$.

\section{Preparo dos inóculos}

Os inóculos, obtidos a partir das culturas-estoque, foram obtidos pelo crescimento em caldo simples a $30{ }^{\circ} \mathrm{C}$ e $150 \mathrm{rpm}$ por $24 \mathrm{~h}$. O caldo simples tem a mesma composição da gelose simples, isenta de ágar-ágar ${ }^{13}$.

\section{Experimentos de fotólise e fotocatálise}

O fotocatalisador usado neste trabalho foi $\mathrm{TiO}_{2}$ (P-25 Degussa). $\mathrm{O}$ dióxido de titânio foi adicionado às soluções contendo as suspensões celulares imediatamente antes da reação fotocatalítica.

Os experimentos foram conduzidos em béquers de $250 \mathrm{~mL}$, contendo $50 \mathrm{~mL}$ de solução com o inóculo, preparado no momento do teste, mais a quantidade adequada do catalisador. As amostras foram mantidas continuamente sob agitação. A irradiação por luz UV foi fornecida por uma lâmpada germicida Toshiba GL 30W, com uma irradiância de cerca de $8 \mathrm{~W} \mathrm{~m}^{-2}$, para comprimento de onda $(\lambda)$ igual a $254 \mathrm{~nm}$, ou por uma lâmpada de vapor de mercúrio de $250 \mathrm{~W}$ Philips HPL-N (sem o bulbo de vidro), com irradiância de cerca de $108 \mathrm{~W} \mathrm{~m}^{-2}$ para $\lambda>254 \mathrm{~nm}$. Foi utilizado um radiômetro Black Ray ${ }^{\circledR}$, J-225, UVP Inc., Upland, CA 91786 USA, específico para $\lambda<300 \mathrm{~nm}$, para as determinações das irradiâncias. As lâmpadas foram posicionadas a uma distância de $12 \mathrm{~cm}$ da superfície da suspensão. Os experimentos foram conduzidos em sistemas distintos, todos em duplicata, com e sem $\mathrm{TiO}_{2}$, variando-se o tempo de exposição à irradiação UV de 5 a 20 min; concentração de $\mathrm{TiO}_{2}$ de 0 a $1 \mathrm{mg} \mathrm{mL}^{-1}$ e concentração celular inicial de $10^{4}$ a $10^{10} \mathrm{UFC} \mathrm{mL}^{-1}$ (número de Unidades Formadoras de Colônias por $\mathrm{mL}$ da amostra).

\section{Determinação da viabilidade celular}

A quantificação de células viáveis nas suspensões celulares, que foram submetidas à irradiação UV, na presença e ausência de $\mathrm{TiO}_{2}$, foi realizada pela técnica de semeadura em placa, empregando-se meio de gelose simples e incubação a $35-37{ }^{\circ} \mathrm{C}$ por $24-48 \mathrm{~h}$. Os plaqueamentos foram feitos em duplicata e expressos UFC $\mathrm{mL}^{-1}$.

Através da Equação (1), calcula-se a taxa de morte dos microrganismos, e através da Equação (2), encontra-se a taxa de sobrevivência, a qual foi utilizada nas tabelas com os resultados deste trabalho.

$\frac{\eta_{0}-\eta_{t}}{\eta_{0}} \cdot 100=$ eficiência $(\%)$

$\frac{\eta_{t}}{\eta_{0}} \cdot 100=$ sobrevivência (\%)

onde $\eta_{0}=$ número de células vivas iniciais e $\eta_{t}=$ número de células vivas ao final da aplicação dos processos.

\section{RESULTADOS}

Efeito da intensidade luminosa e das concentrações celulares de Escherichia coli e Pseudomonas sp. na atividade bactericida da irradiação UV, com e sem $\mathrm{TiO}_{2}$

Ao se avaliar a intensidade luminosa na atividade bactericida, utilizou-se apenas a espécie bacteriana Escherichia coli. Conforme os resultados dos experimentos registrados na Tabela 1, utilizandose concentração bacteriana de $\sim 10^{9} \mathrm{UFC} \mathrm{mL}^{-1}$, observou-se ausência de crescimento após a irradiação UV, com e sem $\mathrm{TiO}_{2}$, a partir de $10 \mathrm{~min}$, tempo mínimo estipulado nos experimentos. No entanto, nos resultados registrados na Tabela 2, com uma lâmpada de intensi-

Tabela 1. Efeito da concentração celular inicial de Escherichia coli (UFC mL-1) sobre a taxa de sobrevivência, após irradiação no UV, empregando lâmpada de mercúrio de alta pressão, com ou sem $\mathrm{TiO}_{2}\left(1 \mathrm{mg} \mathrm{mL} \mathrm{mL}^{-1}\right)$

\begin{tabular}{|c|c|c|c|c|c|}
\hline \multicolumn{3}{|c|}{ Concentrações celulares iniciais (UFC mL $\mathrm{mL}^{-1}$ ) } & $(4,66 \pm 0,60) \cdot 10^{13}$ & $(1,05 \pm 0,11) \cdot 10^{9}$ & $(3,16 \pm 0,40) \cdot 10^{6}$ \\
\hline $\begin{array}{l}\text { Concentrações celulares finais } \\
\text { sem } \mathrm{TiO}_{2}\left(\mathrm{UFC} \mathrm{mL}^{-1}\right)\end{array}$ & $10 \mathrm{~min}$ & $\%$ sobrev. & $\begin{array}{c}(1,80 \pm 0,12) \cdot 10^{4} \\
3,86 \cdot 10^{-8}\end{array}$ & $\begin{array}{l}\text { Zero } \\
\text { Zero }\end{array}$ & $\begin{array}{l}\text { Zero } \\
\text { Zero }\end{array}$ \\
\hline $\begin{array}{l}\text { Concentrações celulares finais } \\
\text { com } \mathrm{TiO}_{2}\left(\mathrm{UFC} \mathrm{mL} \mathrm{mL}^{-1}\right)\end{array}$ & $\begin{array}{l}10 \mathrm{~min} \\
20 \mathrm{~min} \\
40 \mathrm{~min}\end{array}$ & $\begin{array}{l}\% \text { sobrev. } \\
\% \text { sobrev. } \\
\% \text { sobrev. }\end{array}$ & $\begin{array}{c}(3,09 \pm 0,20) \cdot 10^{7} \\
6,63 \cdot 10^{-5} \\
(2,34 \pm 0,32) \cdot 10^{7} \\
5,02 \cdot 10^{-5} \\
(4,23 \pm 0,60) \cdot 10^{5} \\
9,08 \cdot 10^{-7}\end{array}$ & $\begin{array}{l}\text { Zero } \\
\text { Zero } \\
\text { Zero } \\
\text { Zero } \\
\text { Zero } \\
\text { Zero }\end{array}$ & $\begin{array}{l}\text { Zero } \\
\text { Zero } \\
\text { Zero } \\
\text { Zero } \\
\text { Zero } \\
\text { Zero }\end{array}$ \\
\hline
\end{tabular}

Lâmpada de vapor de mercúrio $250 \mathrm{~W}$ Philips HPL-N; irradiância: $108 \mathrm{~W} \mathrm{~m} \mathrm{~m}^{-2} \mathrm{em} \lambda>254 \mathrm{~nm}$ 
dade menor, após 20 min de irradiação UV, com e sem $\mathrm{TiO}_{2}$, concentrações bacterianas de $3,13 \times 10^{4} \mathrm{UFC} \mathrm{mL}^{-1}$ e $2,87 \times 10^{2}$ UFC $\mathrm{mL}^{-1}$, respectivamente, foram detectadas. Embora as taxas de sobrevivência destes valores $\left(1,50 \times 10^{-3} \%\right.$ e $1,38 \times 10^{-5} \%$, respectivamente) sejam desprezíveis, estas quantidades maiores de células viáveis, comparadas com os resultados dos experimentos da Tabela 1, justificamse pela menor intensidade luminosa empregada. A maior potência da lâmpada empregada nos experimentos mostrados na Tabela 1, determinou uma maior eficiência na atividade bactericida.

Comparando-se os resultados experimentais das Tabelas 2 e 3 e observando-se as maiores concentrações bacterianas iniciais, ou seja, $\sim 10^{9} \mathrm{UFC} \mathrm{mL}^{-1}$ para E. coli $\mathrm{e} \sim 10^{10} \mathrm{UFC}_{\mathrm{mL}^{-1}}$ para Pseudomonas sp., observou-se ausência de crescimento após 20 min de irradiação UV sem $\mathrm{TiO}_{2}$ para Pseudomonas sp., o que não ocorreu com E. coli, mesmo com concentração celular inicial cerca de dez vezes menor em relação à concentração de Pseudomonas sp. Assim, a eficiência do tratamento sem $\mathrm{TiO}_{2}$ foi maior na eliminação de Pseudomonas sp.

No caso de amostras com uma concentração celular intermediária para os dois gêneros bacterianos $\left(\sim 10^{6} \mathrm{UFC} \mathrm{mL}^{-1}\right)$, a eficiência foi $100 \%$ para o tratamento com $\mathrm{TiO}_{2}$, quando se usou E.coli, e $100 \%$ para o tratamento sem $\mathrm{TiO}_{2}$, quando se utilizou Pseudomonas sp. Ambos os tratamentos foram $100 \%$ eficientes para os dois microrganismos ao se utilizar a concentração celular inicial $\sim 10^{4} \mathrm{UFC}^{-1}$. A redução bacteriana ficou acima de $99,9 \%$. Os diferentes resultados obtidos justificam-se pela utilização de gêneros bacterianos diferentes, uma vez que diferentes gêneros e espécies de bactérias apresentam uma variedade de propriedades morfológicas e fisiológicas que levam a distintas respostas celulares, mesmo quando essas células são submetidas às mesmas condições experimentais.

\section{Efeito do tempo de exposição à irradiação UV, com e sem $\mathrm{TiO}_{2}$, sobre a atividade bactericida}

Os resultados apresentados na Tabela 4 mostram que após 20 min de irradiação UV, com e sem $\mathrm{TiO}_{2}$, os tratamentos foram eficientes para a completa eliminação de Pseudomonas sp., ressaltandose uma diminuição bastante significativa já a partir de 5 min. Com relação à E.coli, tendo uma concentração inicial cerca de $10^{2}$ vezes menor $\left(\sim 10^{8}\right.$ UFC $\left.\mathrm{mL}^{-1}\right)$ em relação à concentração inicial de Pseudomonas sp. $\left(\sim 10^{10} \mathrm{UFC}_{\mathrm{mL}^{-1}}\right)$, também foi atingida uma grande eficiência na eliminação de células em todos os tempos de exposição. Apesar do elevado percentual na eliminação bacteriana após os tratamentos, pode-se verificar, de maneira geral, que o número final de células viáveis de E. coli foi maior que para Pseudomonas sp., mesmo partindo-se de uma concentração inicial menor. Mesmo assim, os processos foram considerados eficientes para os dois microrganismos devido à baixa taxa de sobrevivência e, ressaltando-se mais uma vez, o comportamento dos diferentes gêneros bacterianos, determinando um número final distinto de células.

\section{Efeito da concentração de $\mathrm{TiO}_{2}$ na atividade bactericida}

A Tabela 5 ilustra o efeito de diferentes concentrações de $\mathrm{TiO}_{2}$ na eliminação das células de E.coli e Pseudomonas sp. Os resultados confirmam que a irradiação UV com $\mathrm{TiO}_{2}$ exibe atividade bactericida e que a desinfecção está relacionada à dosagem de $\mathrm{TiO}_{2}$ usada até a concentração de estudo $\left(1 \mathrm{mg} \mathrm{mL}^{-1}\right)$. As concentrações acima deste valor podem resultar na diminuição da eficiência bactericida pela possível redução da intensidade da radiação UV sobre a suspensão celular com $\mathrm{TiO}_{2}$, causada pelas partículas do catalisador em suspensão, encobrindo as células microbianas ${ }^{14}$.

\section{DISCUSSÃO}

Dos resultados obtidos, assim como de estudos desenvolvidos por vários outros pesquisadores ${ }^{7,14-19}$ sobre a atividade fotobiológica do $\mathrm{TiO}_{2}$, observou-se que as menores concentrações de células viáveis, obtidas após o tratamento, corresponderam às menores concentrações celulares iniciais utilizadas, reportando também, a influência da intensidade luminosa, do tempo de irradiação, da concentração do $\mathrm{TiO}_{2}$ e das diferentes fotossensibilidades dos microrganismos na capacidade do $\mathrm{TiO}_{2}$ para exercer sua atividade bactericida.

Segundo Maness et al. ${ }^{14}$, concentrações de $\mathrm{TiO}_{2}$ maiores que $1 \mathrm{mg} \mathrm{mL}^{-1}$ reduzem a eficiência bactericida. A turbidez causada pelas partículas do $\mathrm{TiO}_{2}$ em suspensão e o baixo poder de penetração da luz UV reduzem a intensidade da radiação sobre as células

Tabela 2. Efeito da concentração celular inicial de Escherichia coli $\left(\mathrm{UFC} \cdot \mathrm{mL}^{-1}\right)$ sobre a taxa de sobrevivência, após irradiação no UV, com ou sem $\mathrm{TiO}_{2}\left(1 \mathrm{mg} \mathrm{mL}^{-1}\right)$

\begin{tabular}{|c|c|c|c|c|c|}
\hline \multicolumn{3}{|c|}{ Concentrações celulares iniciais $\left(\mathrm{UFC} \cdot \mathrm{mL}^{-1}\right.$ ) } & $(2,08 \pm 0,07) \cdot 10^{9}$ & $(5,93 \pm 0,63) \cdot 10^{6}$ & $(2,78 \pm 0,40) \cdot 10^{4}$ \\
\hline $\begin{array}{l}\text { Concentrações celulares finais } \\
\text { sem } \mathrm{TiO}_{2}\left(\mathrm{UFC} \mathrm{mL} \mathrm{mL}^{-1}\right)\end{array}$ & $20 \mathrm{~min}$ & $\%$ sobrev. & $\begin{array}{c}(2,87 \pm 0,64) \cdot 10^{2} \\
1,38 \cdot 10^{-5}\end{array}$ & $\begin{array}{c}(1,00 \pm 0,10) \cdot 10 \\
1,69 \cdot 10^{-4}\end{array}$ & $\begin{array}{l}\text { Zero } \\
\text { Zero }\end{array}$ \\
\hline 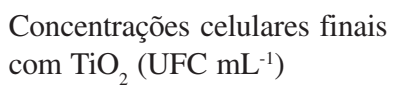 & $20 \mathrm{~min}$ & $\%$ sobrev. & $\begin{array}{c}(3,13 \pm 0,12) \cdot 10^{4} \\
1,50 \cdot 10^{-3}\end{array}$ & $\begin{array}{l}\text { Zero } \\
\text { Zero }\end{array}$ & $\begin{array}{l}\text { Zero } \\
\text { Zero }\end{array}$ \\
\hline
\end{tabular}

Lâmpada germicida UV Toshiba GL $30 \mathrm{~W}$; irradiância: $~ 8 \mathrm{~W} \mathrm{~m}^{-2}$ em $\lambda=254 \mathrm{~nm}$

Tabela 3. Efeito da concentração celular inicial de Pseudomonas sp. (UFC mL $\mathrm{mL}^{-1}$ ) sobre a taxa de sobrevivência, após irradiação no UV, com ou sem $\mathrm{TiO}_{2}\left(1 \mathrm{mg} \cdot \mathrm{mL}^{-1}\right)$

\begin{tabular}{|c|c|c|c|c|c|}
\hline \multicolumn{3}{|c|}{ Concentrações celulares iniciais $\left(\mathrm{UFC} \cdot \mathrm{mL}^{-1}\right)$} & $(6,00 \pm 0,10) \cdot 10^{10}$ & $(3,91 \pm 0,30) \cdot 10^{6}$ & $(9,20 \pm 0,11) \cdot 10^{4}$ \\
\hline \multirow{2}{*}{$\begin{array}{l}\text { Concentrações celulares finais } \\
\text { sem } \mathrm{TiO}_{2}\left(\mathrm{UFC} \mathrm{mL}^{-1}\right)\end{array}$} & \multirow[t]{2}{*}{$20 \min$} & & Zero & Zero & Zero \\
\hline & & $\%$ sobrev. & Zero & Zero & Zero \\
\hline \multirow{2}{*}{$\begin{array}{l}\text { Concentrações celulares finais } \\
\text { com } \mathrm{TiO}_{2}\left(\mathrm{UFC} \mathrm{mL} \mathrm{mL}^{-1}\right)\end{array}$} & \multirow[t]{2}{*}{$20 \mathrm{~min}$} & & $(2,42 \pm 0,90) \cdot 10^{4}$ & $(1,70 \pm 0,11) \cdot 10^{3}$ & Zero \\
\hline & & $\%$ sobrev. & $4,03 \cdot 10^{-5}$ & $4,35 \cdot 10^{-2}$ & Zero \\
\hline
\end{tabular}

Lâmpada germicida UV Toshiba GL $30 \mathrm{~W}$; irradiância: $~ 8 \mathrm{~W} \mathrm{~m}^{-2}$ em $\lambda=254 \mathrm{~nm}$ 
Tabela 4. Efeito do tempo de irradiação no UV, com ou sem $\mathrm{TiO}_{2}\left(1 \mathrm{mg} \mathrm{mL}^{-1}\right)$, sobre a taxa de sobrevivência de Escherichia coli e Pseudomonas sp.



Lâmpada germicida UV Toshiba GL $30 \mathrm{~W}$; irradiância: $~ 8 \mathrm{~W} \mathrm{~m}^{-2} \mathrm{em} \lambda=254 \mathrm{~nm}$

Tabela 5. Efeito da concentração de $\mathrm{TiO}_{2}\left(\mathrm{mg} \mathrm{mL}^{-1}\right)$ com irradiação no UV sobre a taxa de sobreviência de Escherichia coli e Pseudomonas sp.

Concentrações celulares iniciais $\left(\mathrm{UFC} \mathrm{mL}^{-1}\right)$

Microrganismos

$$
\text { E. coli Pseudomonas sp. }
$$

$(4,00 \pm 0,23) \cdot 10^{9}$ $(6,33 \pm 0,13) \cdot 10^{10}$

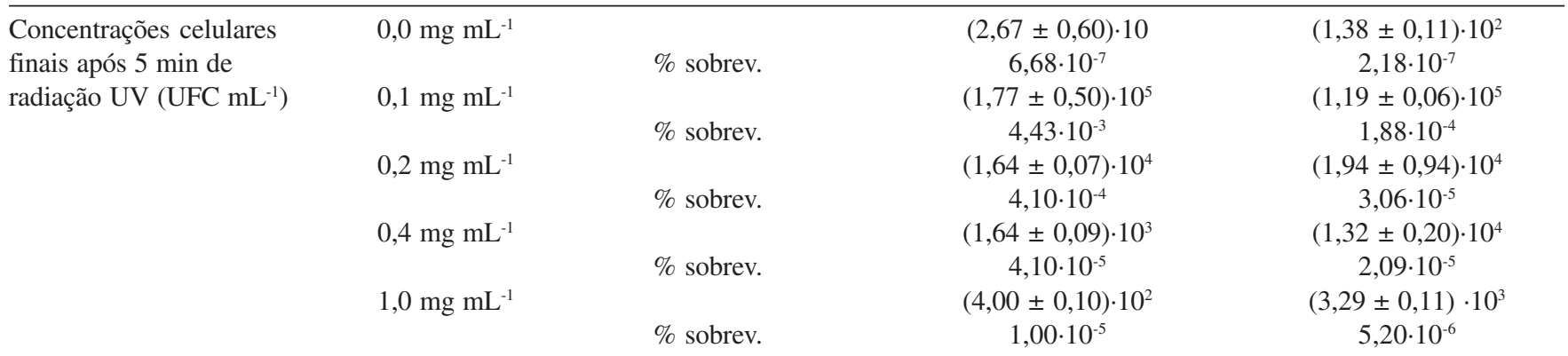

Lâmpada germicida UV Toshiba GL $30 \mathrm{~W}$; irradiância: $\sim 8 \mathrm{~W} \mathrm{~m}^{-2} \mathrm{em} \lambda=254 \mathrm{~nm}$

microbianas ${ }^{20-23}$. Portanto, no tratamento com radiação UV e $\mathrm{TiO}_{2}$ ocorre a combinação de dois processos, o ataque das células pelos radicais hidroxila $\left({ }^{\circ} \mathrm{OH}\right)$, gerados pela degradação na superfície do fotocatalisador e, também, a absorção direta da radiação UV pelas células, sendo que esta é sem dúvida a responsável por parte significativa da inativação celular.

A redução da transmissão da radiação UV pode surgir também em decorrência da deposição de sais pouco solúveis (por exemplo, $\mathrm{CaCO}_{3}$ ) em volta da lâmpada, ou devido à redução da eficiência da lâmpada pelo excesso de uso da mesma ${ }^{24}$. Esta possibilidade está afastada, pois a emissão da lâmpada foi monitorada em todos os experimentos.

A eficiência da desinfecção por radiação UV também pode ser afetada pela presença de alguns compostos, como ferro, sulfeto, nitrito e fenol, que absorvem radiação UV no comprimento de onda de 254 nm. Ainda, segundo Ireland et al..$^{25}$, a presença de matéria orgânica reduz a cinética da inativação, competindo ostensivamente com as bactérias pelo radical hidroxila. Este fato foi verificado em nossos experimentos quando, por engano, a suspensão celular foi feita não em solução salina, mas em meio nutritivo. Neste experimento particular, não foi possível ser feita a quantificação, pois as baixas diluições estabelecidas para as contagens rotineiras, determinaram uma grande concentração de células viáveis finais, provavelmente a eficiência da desinfecção das células foi afetada pela presença da carga orgânica do meio nutriente.

A luz ultravioleta é absorvida por muitos compostos intracelulares, mas o DNA é o que sofre o maior dano. A maior atividade bactericida ocorre em $260 \mathrm{~nm}$, que é o comprimento de onda mais fortemente absorvido pelo DNA. Após o DNA ter sido exposto à luz UV, ocorre a formação de dímeros de pirimidina. Caso esses dímeros não sejam removidos por enzimas específicas de reparo intracelular, a replicação do DNA pode ser inibida ou alterada, causando mortes ou mutações. Assim, uma desvantagem significativa dos processos de desinfecção UV para monitorar os microrganismos de veiculação 
hídrica, tanto em água potável quanto em água residuária, seria a capacidade dos microrganismos para reparar os danos causados na estrutura do seu DNA, caso uma dose subletal seja usada ${ }^{26-29}$.

Os mecanismos de recuperação dos microrganismos irradiados com UV incluem os processos enzimáticos da fotorreativação e da recuperação no escuro. A fotorreativação, que resulta na remoção dos dímeros do DNA, ocorre na presença de radiação na faixa de comprimento de onda de $310-480 \mathrm{~nm}$, e a recuperação no escuro ocorre, como seu nome sugere, na ausência de luz. Num processo de tratamento com luz UV para desinfecção de efluentes, o tempo de residência dentro da tubulação, seguido pela disposição em águas superficiais, favorecem a ocorrência de ambos os mecanismos de regeneração celular ${ }^{24,26-29}$. Portanto, deve-se assegurar uma dose suficiente de UV no processo para garantir a inviabilização celular.

Otaki et al. ${ }^{9}$ estudaram a inativação de três espécies de microrganismos, Escherichia coli, bacteriófago Q $\beta$ e Cryptosporidium parvum, por desinfecção fotocatalítica com $\mathrm{TiO}_{2}$, utilizando irradiação UV-C $\left(0,2 \mathrm{~mW} \mathrm{~cm}{ }^{-2}\right.$, em $\left.254 \mathrm{~nm}\right)$ ou luz negra $\left(7,0 \mathrm{~mW} \mathrm{~cm} \mathrm{~cm}^{-2}, \mathrm{em}\right.$ $360 \mathrm{~nm}$ ). Como as células de Escherichia coli foram sensíveis à irradiação UV-C e UV-A, não houve diferença significativa entre a inativação feita com e sem $\mathrm{TiO}_{2}$; quanto aos vírus, apresentaram sensibilidade somente para irradiação UV-C, e assim o efeito do $\mathrm{TiO}_{2}$ não pôde ser observado nesta irradiação. Contudo, o efeito aditivo do $\mathrm{TiO}_{2}$ pôde ser observado claramente, na inativação de $\mathrm{Q} \beta$, com irradiação UV-A, e de Cryptosporidium parvum, com irradiação UVC ou UV-A, porque esses microrganismos foram resistentes à irradiação da luz. Apesar da eficiência fotocatalítica ter sido igual em ambos os reatores, a inativação fotocatalítica para o protozoário foi mais rápida com UV-C que com UV-A.

De acordo com Ashikaga et al. ${ }^{30}, \mathrm{TiO}_{2}$ absorve UV-A eficientemente e exibe atividade fotocatalítica. Recentemente, a ação bactericida da fotocatálise heterogênea $\left(\mathrm{UV}-\mathrm{A} / \mathrm{TiO}_{2}\right)$ foi testada em microrganismos com diferentes fotossensibilidades ${ }^{18}$. Alta eficiência foi encontrada em todos os casos estudados, particularmente para o mais resistente, Enterobacter cloacae. Este microrganismo normalmente é encontrado no solo e na água e, devido a um eficiente sistema defensivo antioxidante ${ }^{31}$, não é inativado pela irradiação UVA. Em todos os casos estudados, doses subletais de UV-A na presença de $\mathrm{TiO}_{2}$ foram eficientes na eliminação microbiana.

A atividade bactericida do processo fotocatalítico com $\mathrm{TiO}_{2}$, usando irradiação UV-A e oxigênio como agente oxidante, tem sido atribuída à geração de espécies reativas de oxigênio ${ }^{14}$. Os radicais hidroxila $\left({ }^{\circ} \mathrm{OH}\right)$ e os ânions superóxido $\left(\mathrm{O}_{2}^{-}\right)$, altamente reativos com amostras biológicas, são considerados as espécies principais produzidas durante o processo ${ }^{25,32-34}$. Outras espécies, como peróxido de hidrogênio $\left(\mathrm{H}_{2} \mathrm{O}_{2}\right)$, radical hidroperoxil $\left(\mathrm{HO}_{2}{ }^{\circ}\right)$ e oxigênio singlete $\left({ }^{1} \mathrm{O}_{2}\right)$ têm sido também consideradas ${ }^{32,34,35}$.

A grande sensibilidade de Pseudomonas aruginosa a UV-A foi reportada por Fernández et al. ${ }^{36}$. A exposição à irradiação UV-A (365 $\mathrm{nm}, 120 \mathrm{~kJ} \mathrm{~m}^{-2} \mathrm{~h}^{-1}$ ) foi eficaz na eliminação desses microrganismos, mas não afetou a viabilidade das células de Escherichia coli.

Estudos ${ }^{33,37-40}$ sobre a ação microbicida do processo fotocatalítico com $\mathrm{TiO}_{2}$ revelaram que os vírus são mais sensíveis ao processo, seguidos pelas células bacterianas, e estas pelos esporos bacterianos. Isso sugere que diferentes microrganismos respondem de maneira diferente ao fotocatalisador $\mathrm{TiO}_{2}$ devido às suas diferenças estruturais, particularmente no que diz respeito à complexidade e espessura do envelope celular.

Segundo Huang et al. ${ }^{35}$, a descontaminação feita com radiação UV e $\mathrm{TiO}_{2}$ é assegurada pelos maiores prejuízos causados com o uso do catalisador $\mathrm{TiO}_{2}$. A ação oxidativa exercida pelo processo UV/ $\mathrm{TiO}_{2}$ ocasiona danos na parede celular e na membrana citoplasmática. A ação fotocatalítica aumenta progressivamente a permeabilidade celular, permitindo o efluxo livre do conteúdo intracelular, que conduz finalmente à morte celular. As partículas livres de $\mathrm{TiO}_{2}$ podem também penetrar nas células danificadas, e o ataque direto posterior nos componentes intracelulares, como enzimas ${ }^{15,37}$ e DNA ${ }^{41}$, pode acelerar a morte celular. Com esse mecanismo, eles enfatizaram a importância da parede celular e da membrana citoplasmática como os alvos principais do ataque do $\mathrm{TiO}_{2}$.

Sunada et al. ${ }^{19}$ estudando o mecanismo de inativação de células de E. coli através da ação oxidativa exercida pelo processo $\mathrm{UV} / \mathrm{TiO}_{2}$, observaram que a reação é iniciada por uma decomposição parcial da membrana externa, causada pelas espécies reativas produzidas no processo fotocatalítico. Eles observaram que nessa etapa não há a perda total da viabilidade. Contudo, há alterações na permeabilidade da membrana externa, possibilitando que as espécies reativas alcancem a membrana citoplasmática, e ocorra a peroxidação dos lipídeos da membrana ${ }^{14}$. Com as alterações estruturais e funcionais da membrana citoplasmática ${ }^{42-44}$, ocorre a perda da viabilidade e, finalmente, a morte celular.

Oguma et al. ${ }^{45}$ observaram que a velocidade de fotorreativação de E.coli, após irradiação $\mathrm{UV} / \mathrm{TiO}_{2}$, foi menor que aquela ocorrida somente com irradiação UV, apesar de nenhuma diferença ter ocorrido entre as velocidades de inativação pela irradiação UV, com e sem $\mathrm{TiO}_{2}$. Assim, mesmo que a irradiação feita somente com UV tenha uma boa eficiência na inativação da biomassa, a presença de $\mathrm{TiO}_{2}$, pelos motivos acima expostos, poderá assegurar maior benefício ambiental, uma vez que promove danos irreversíveis às células bacterianas, evitando uma fotorreativação posterior.

\section{CONCLUSÕES}

Dos resultados obtidos nas condições experimentais utilizadas, concluiu-se que a taxa de sobrevivência das espécies bacterianas estudadas diminuiu quando se reduziu a concentração celular inicial, aumentando-se a intensidade luminosa, o tempo de exposição à irradiação UV ou a dosagem de $\mathrm{TiO}_{2}$ até a concentração de $1 \mathrm{mg} \mathrm{mL}^{-1}$.

Foi detectada maior resistência para Escherichia coli em relação à Pseudomonas sp. para os dois processos.

O desempenho dos processos de fotodegradação, com ou sem $\mathrm{TiO}_{2}$, mostrou-se eficiente na descontaminação de água, podendo ser um método viável no tratamento de água.

\section{REFERÊNCIAS}

1. Barros, R. T. V.; Chernicharo, C. A. L.; Héller, L.; Von Sperling, M.; Manual de Saneamento e Proteção Ambiental para os Municípios, Saneamento DESA-UFMG 1996, vol. 2, cap. 5.

2. Andreozzi, R.; Caprio, V.; Insola, A.; Marotta, R.; Catal. Today 1999, 53, 51 .

3. Bertazzoli, R.; Pelegrini, R.; Quim. Nova 2002, 25, 477.

4. Nogueira, R. F. P.; Jardim, W. F.; Quim. Nova 1998, 21, 69.

5. Ziolli, R. L.; Jardim, W. F.; Quim. Nova 1998, 21, 319.

6. Tryk, D. A.; Fujishima, A.; Honda, K.; Electrochim. Acta 2000, 45, 2363.

7. Watts, R. J.; Kong, S.; Orr, M. P.; Miller, G. C.; Henry, B. E.; Water Res. 1995, 29, 95

8. Melián, J. A. H.; Rodríguez, J. M. D.; Suárez, A. V.; Rendón, E. T.; Campo, C. V.; Arana, J.; Penã, J. P.; Chemosphere 2000, 41, 323.

9. Otaki, M.; Hirata, T.; Ohgaki, S.; Water Sci. Technol. 2000, 42, 103.

10. Dunlop, P. S. M.; Byrne, J. A.; Manga, N.; Eggins, B. R.; J. Photochem. Photobiol., A 2002, 148, 355.

11. Kondo, M. M.; Orlanda, J. F. F.; Ferreira, M. G. A. B.; Grassi, M. T.; Quim. Nova 2003, 26, 133.

12. Pelczar Jr., M. J.; Chan, E. C. S.; Krieg, N. R.; Microbiologia Conceitos e Aplicações, $2^{\text {nd }}$ ed., Makron Books, 1996.

13. Rosemberg, J. A.; Penha, E. M.; Técnicas Básicas de Microbilogia, Apostila - Escola de Química da Universidade Federal do Rio de Janeiro, 1989.

14. Maness, P-C.; Smolinski, S.; Blake, D. M.; Huang, Z.; Wolfrum, E. J.; Jacoby, W. A.; Appl. Environ. Microbiol. 1999, 65, 4094. 
15. Matsunaga, T.; Tomoda, R.; Nakajima, T.; Nakamura, N.; Komine, T.; Appl. Environ. Microbiol. 1988, 54, 1330.

16. Wei, C.; Lin, W. Y.; Zainal, Z.; Williams, N. E.; Zhu, K.; Kruzic, A. P.; Smith, R. L.; Rajeshwar, K.; Environ. Sci. Technol. 1994, $28,934$.

17. Bekbölet, M.; Water Sci. Technol. 1997, 35, 95.

18. Ibánez, J. A.; Litter, M. I.; Pizarro, R.A.; J. Photochem. Photobiol., A 2003, $157,81$.

19. Sunada, K.; Watanable, T.; Hashimoto, K.; J. Photochem. Photobiol., A 2003, 156, 227.

20. Qualls, R. G.; Flynn, M. P.; Johnson, J. D.; J. Wat. Poll. Control Fed. 1983, $55,1280$.

21. Baer, G.; Public Works 1979, 59

22. Block, S. S.; Goswami, D. W.; Sol. Eng. 1995, 1, 431.

23. Cooper, A. T.; Goswami, D. Y.; Block, S. S.; J. Adv. Oxid. Technol. 1998, 3,151 .

24. Chan, Y. Y.; Killick, E. G.; Water Res. 1995, 5, 1373.

25. Ireland, J. C.; Klostermann, P.; Rice, E. W.; Clark, R. M.; Appl. Environ. Microbiol. 1993, 59, 1668.

26. Harris, G. D.; Adams, V. D.; Sorensen, D. L.; Curtis, M. S.; Water Res. 1987, 6, 687.

27. Lindenauer, K. G.; Darby, J. L; Water Res. 1994, 4, 805.

28. Kashimada, K.; Kamido, N.; Yamamoto, K.; Ohgaki, S.; Water Sci. Technol. 1996, 33, 261.

29. Tosa, K.; Hirata, T.; Water Res. 1999, 2, 361.

30. Ashikaga, T.; Wada, M.; Kobayashi, H.; Mori, M.; Katsumura, Y.; Fukui, H.; Kato, S.; Yamaguchi, M.; Takamatsu, T.; Mutat. Res. 2000, 466, 1.
31. Oppezzo, O. J.; Pizarro, R. A.; J. Photochem. Photobiol., B 2001, 62, 158.

32. Blake, D. M.; Maness, P. C.; Huang, Z.; Wolfrum, E. J.; Huang, J.; Sep. Purif. Methods 1999, 28, 1.

33. Pham, H. N.; Dowell, T. Mc; Wilkins, E.; J. Environ. Sci. Health 1995, 3 , 627.

34. Kikuchi, Y.; Sunada, K.; Iyoda, T.; Hashimoto, K.; Fujishima, A.; J. Photochem. Photobiol., A 1997, 106, 51.

35. Huang, Z.; Maness, P-C.; Blake, D. M.; Wolfrum, E. J.; Smolinski, S. L.; Jacoby, W. A.; J. Photochem. Photobiol., A 2000, 130, 163.

36. Fernández, R. O.; Pizarro, R. A.; Photochem. Photobiol. 1996, 64, 334.

37. Matsunaga, T.; Tomoda, R.; Nakajima, T.; Wake, H.; FEMS Microbiol. Lett. 1985, 29, 211.

38. Saito, T.; Iwase, T.; Horis, J.; Morioka, T.; J. Photochem. Photobiol., B 1992, 14, 369.

39. Lee, S.; Nishida, K.; Otaki, M.; Ohgaki, S.; Water Sci. Technol. 1997, 35, 101 .

40. Sjogren, J. C.; Sierka, R. A.; Appl. Environ. Microbiol. 1994, 60, 344.

41. Wamer, W. G.; Yin, J. J.; Wei, R. R.; Free Radical Biol. Med. 1997, 23, 851

42. Lynch, R. E.; Fridovich, I.; J. Biol. Chem. 1978, 253, 1838.

43. Girotti, A. W.; Thomas, J. P.; J. Biol. Chem. 1984, 259, 1744

44. Ginkek, G. V.; Sevanian, A.; Methods Enzymol. 1994, 233, 273.

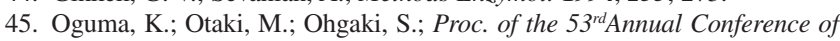
the JSCE 1998, 7, 250. 